\title{
Frequency of c.35delG Mutation in GJB2 Gene (Connexin 26) in Syrian Patients with Nonsyndromic Hearing Impairment
}

\author{
Hazem Kaheel, ${ }^{1}$ Andreas Breß, ${ }^{1}$ Mohamed A. Hassan, ${ }^{1,2}$ Aftab Ali Shah, ${ }^{3}$ Mutaz Amin, \\ Yousuf H. Y. Bakhit, ${ }^{5}$ and Marlies Kniper ${ }^{1}$ \\ ${ }^{1}$ Universitäts-HNO-Klinik Tübingen, Tübingen, Germany \\ ${ }^{2}$ Department of Bioinformatics, Africa City of Technology, Khartoum, Sudan \\ ${ }^{3}$ Faculty of Biotechnology, University of Malakand, Malakand, Pakistan \\ ${ }^{4}$ Department of Biochemistry, Faculty of Medicine, University of Khartoum, Khartoum, Sudan \\ ${ }^{5}$ Department of Basic Medical Sciences, Faculty of Dentistry, University of Khartoum, Khartoum, Sudan
}

Correspondence should be addressed to Mutaz Amin; mtz88@hotmail.co.uk

Received 23 April 2017; Revised 4 July 2017; Accepted 11 July 2017; Published 6 December 2017

Academic Editor: Xinhua Shu

Copyright (C) 2017 Hazem Kaheel et al. This is an open access article distributed under the Creative Commons Attribution License, which permits unrestricted use, distribution, and reproduction in any medium, provided the original work is properly cited.

Background. Hearing impairments (HI) are the most common birth defect worldwide. Very large numbers of genes have been identified but the most profound is GJB2. The clinical interest regarding this gene is very pronounced due to its high carrier frequency (0.5-5.4\%) across different ethnic groups. This study aimed to determine the prevalence of common GJB2 mutations in Syrian patients with profound sensorineural HI. Methods. We carried out PCR, restriction enzyme based screening, and sequencing of 132 Syrian patients diagnosed clinically with hereditary deafness for different GJB2 mutations. Results. The result revealed that, in GJB2 gene, c.35delG is the most prevalent among affected studied subjects (13.64\%), followed by c.457G>A (2.4\%). Conclusion. The benefit of this study on the one hand is its first report of prelingual deafness causative gene mutations identified by sequencing technology in the Syrian families. It is obvious from the results that the deployment in biomedical research is highly effective and has a great impact on the ability to uncover the cause of genetic variation in different genetic diseases.

\section{Introduction}

Hearing impairments (HI) are one of the most common detected neonatal defects in the world [1]. Of every 1000 newborns, at least two have permanent bilateral sensorineural HI of more than $40 \mathrm{~dB}[2]$. The causes of $\mathrm{HI}$ are equally shared between environment and genetics [3]. Genes causing $\mathrm{HI}$ are numerous and they cause isolated HI (nonsyndromic $\mathrm{HI}$ ) in $70 \%$ of cases or in association with other medical abnormalities (syndromic HI) in the remaining $30 \%$ of cases [4].

$\mathrm{HI}$ occurs more in developing than developed countries [4]. Reported mutations occur more frequently in GJB2 gene, which encodes the gap junction protein connexin 26 (beta2, GJB2) [5]. GJB2 related HI is sometimes severe but the spectrum of variation severity is wide [6]. This gene is of special interest because of its high carrier frequency in many different ethnic groups $(0.5-5.4 \%)[7,8]$.

$35 \mathrm{delG}$ is the most frequent mutation reported in the GJB2 gene [8]. It is found in more than half of all GJB2 mutations discovered so far [9]. This mutation creates a frameshift resulting in a short nonfunctional truncated form of the protein [10]. Additional mutations are continuously discovered worldwide but very few were done in Middle Eastern countries. This study aimed to determine the prevalence of common GJB2 mutations in Syrians patients with profound sensorineural HI.

\section{Material and Methods}

This study was approved by the Ethical committee of the medical faculty (Syria). All subjects were recruited from Aleppo, which lies in the northwestern region of Syria, with the 
TABLE 1: Frequencies of 35delG genotypes among Syrian subjects with nonsyndromic hearing impairment.

\begin{tabular}{lcc}
\hline Our selected group (familial cases) & c.35delG genotype & $N(\%)$ \\
\hline & Homozygote WT* & $109(82.6 \%)$ \\
Only the deaf & Heterozygote 35delG & $2(1.5 \%)$ \\
& Homozygote 35delG & Total \\
& Homozygote WT* & $13.9 \%)$ \\
& $291(86.3 \%)$ \\
All subjects & Heterozygote 35delG & $25(7.4 \%)$ \\
& Homozygote 35delG & $21(6.2 \%)$ \\
& Total & 337 \\
\hline
\end{tabular}

*WT: wild type.

help of deafness related schools and institutes. The examined group consisted of 337 subjects (including 132 affected) from 54 families from Syria, where 2 or more subjects (up to 6) showed a prelingual, profound, sensorineural, bilateral, and nonsyndromic hearing loss within a family.

2.1. Study Population. In this study 175 females and 162 males were participated, with an age range between two and 72 years (mean age 18.2 years). A physical examination was performed to exclude syndromic forms of hearing impairment at Alrazi hospital (Aleppo), ENT examinations such as Tympanometry and BERA (Brainstem Electric Response Audiometry) were also applied at ENT department of the Alrazi hospital.

2.2. Mutation Screening. The mutation screening strategy was to investigate GJB2 gene mutations including $35 \mathrm{del} G$ mutation (OMIM: 121011). First, total genomic DNA was extracted from $10 \mathrm{ml}$ EDTA blood. This was done using a Qiagen Flexigen kits, in accordance with the manufacturer's instructions. By using primer pair [1F: $5^{\prime}$ - AGA CTC AGA GAA GTC TCC CTG-3'/5R: 5'-GCC AGTTTA ACG CAT TGC CC- $3^{\prime}$ ] the complete coding region of the exon of the GJB2 gene was amplified, in order to search for other possible mutations. The PCR product was gel extracted (Gel Extraction Kit, Qiagen) and sequenced using a capillary sequencer CEQ 8000 (Beckman Coulter) and the following PCR primers [2F: $5^{\prime}$-CCA GGC TGC AAG AAC GTG TGC$3^{\prime}$ ], [3R: $5^{\prime}$-GTG TAC CGG AGA CAT GAG-3'], [4F: $5^{\prime}$-GCA GCA TCT TCT TCC GGG TC - $3^{\prime}$ ], [5R: $5^{\prime}$-GCC AGTTTA ACG CAT TGC CC- $\left.3^{\prime}\right], 1 F$, and 5R. Detected mutations were confirmed at least two times and on both DNA strands compared to the reference sequence (Acc. No.: NM_ 004004).

35delG Detection. The frequency of $35 \mathrm{delG}$ variant was detected by PCR (35delG, F (forward): GGTGAGGTTGTGTAAGAGTTGG; 35delG, R (reverse): CTGGTGGAGTGTTTGTTCCCAC), followed by a BsiYI-digest [11]. Patients homozygous for 35delG showed one band with $181 \mathrm{bp}$ and heterozygous patients displayed two bands (181 bp and $207 \mathrm{bp}$ ) after polyacrylamide gel electrophoresis (6\%).

\section{Results}

Two different DNA sequence variants c.35delG and c. $457 \mathrm{G}>\mathrm{A}$ were detected in 54 Syrian families.
c.35delG variant was detected in 9 out of $54(16.7 \%)$ families, 46 of 337 (13.64\%) of subjects, of which 21 were homozygous and 25 were heterozygous for the variant (Table 1).

c. $457 G>A$, (p.V153I) Variant. We detected this variant in 2 out of $54(3.7 \%)$ families, 8 of 337 (2.4\%) subjects, who were only heterozygous for the variation.

\section{Discussion}

The purpose of this study was to identify the genetic basis of hereditary hearing impairment in Syrian patients with nonsyndromic HI, by applying Sanger sequencing leading to the results described above. The 35delG variant which is common worldwide was detected in $16.7 \%$ of Syrian families with nonsyndromic moderate to profound HI. Our results differ from a previous study by Al-Achkar et al. who found $35 \mathrm{delG}$ mutation in $30 \%$ of Syrian families, almost double that in our study [12]. This conflict is probably due to the difference in study areas. Geographical difference in prevalence of congenital deafness was also found previously in Italy [13].

35delG mutation takes place by deletion of one guanine $(G)$ in a run of six guanines extending from position 30 to position 35 in the GJB2 gene causing a frameshift of the coding sequence leading to premature chain termination at the twelfth amino acid [9]. Other studies in small groups found that this variant is responsible for nonsyndromic recessive deafness in a Muslim-Israeli village in the lower Galilee [14]. The frequency of $35 \mathrm{delG}$ variant is very high in Spain, Italy, and Israel [15]. It accounts for approximately $50 \%$ of cases [16] which suggests an evidence for an ancient deletion mutation that had spread in Europe and MiddleEast.

The $c .457 G>A$ variant was found in about one-sixth of Syrian patients with HI. Same similar DNA variant had already been described in many other Asian countries [16, 17]. c.457G $>$ A p.Val153Ile (rs11033186) in the ClinVar database is classified as a benign/likely benign variant. According to ExAc database world frequency of p.457G $>\mathrm{A}$ is 0.01057 (1279/121044 studied chromosomes, of which 922/16488 in South Asia and 299/66564 in Europe). However our results are not strong enough to change the annotation of this variant 
to likely pathogenic, and more studies are needed in this regard.

Based on these results we suggest a routine screening for GJB2 gene mutations in Syrian population which could enhance the chance of detecting affected newborns with sporadic nonsyndromic $\mathrm{HI}$ at an early stage and consequently improves the current diagnostic and therapeutic options. Since GJB2 gene has only one coding exon molecular diagnosis of mutations can be made simple and cost-effective for a daily medical practice. Important for future studies is an increase in selected sample sizes in order to obtain more information regarding possible novel genes and their mutations involved in the hearing process and their faults in hearing impairment.

\section{Conflicts of Interest}

The authors declare that they have no conflicts of interest.

\section{Acknowledgments}

This study was supported by the Jürgen ManchotStiftung. The authors thank all the families, patients, and control individuals for their cooperation in this study.

\section{References}

[1] A. M. Delaney, "Newborn Hearing Screening: Overview, Prevalence of Hearing Loss, The High-Risk Register," http://emedicine.medscape.com/article/836646-overview.

[2] K. Abdul Hadi, A. Salahaldin, A. Al Qahtani et al., "Universal neonatal hearing screening: six years of experience in Qatar," Qatar Medical Journal, vol. 2012, no. 2, pp. 42-50, 2012.

[3] R. J. Smith, A. E. Shearer, M. S. Hildebrand, and G. Van Camp, Deafness and Hereditary Hearing Loss Overview, University of Washington, Seattle, Wash, USA, 1993.

[4] I. Schrijver, "Hereditary non-syndromic sensorineural hearing loss," The Journal of Molecular Diagnostics, vol. 6, no. 4, pp. 275284, 2004.

[5] H. Y. Tang, P. Fang, P. A. Ward et al., "DNA sequence analysis of GJB2, encoding connexin 26: observations from a population of hearing impaired cases and variable carrier rates, complex genotypes, and ethnic stratification of alleles among controls," American Journal of Medical Genetics Part A, vol. 140, no. 22, pp. 2401-2415, 2006.

[6] R. Shemesh, "Hearing Impairment: Definitions, Assessment and Management, International Encyclopedia of Rehabilitation," 2017, http://cirrie.buffalo.edu/encyclopedia/en/article/ $272 /$.

[7] M. Taniguchi, H. Matsuo, S. Shimizu et al., "Carrier frequency of the GJB2 mutations that cause hereditary hearing loss in the Japanese population," Journal of Human Genetics, vol. 60, no. 10, pp. 613-617, 2015.

[8] A. Pandya, K. S. Arnos, X. J. Xia et al., "Frequency and distribution of GJB2 (connexin 26) and GJB6 (connexin 30) mutations in a large North American repository of deaf probands," Genetics in Medicine, vol. 5, no. 4, pp. 295-303, 2003.

[9] M. F. Cordeiro-Silva, A. Barbosa, M. Santiago, M. Provetti, and E. Rabbi-Bortolini, "Prevalências das mutações 35delG/GJB2 e del (GJB6-D13S1830) em portadores de surdez não-sindrômica na população do Espírito Santo-Brasil," Brazilian Journal of Otorhinolaryngology, vol. 76, no. 4, pp. 428-432, 2010.

[10] L. Van Laer, P. Coucke, R. F. Mueller et al., "A common founder for the 35delG GJB2 gene mutation in connexin 26 hearing impairment," Journal of Medical Genetics, vol. 38, no. 8, pp. 515$518,2001$.

[11] K. Storm, S. Willocx, K. Flothmann, and G. Van Camp, "Determination of the carrier frequency of the common GJB2 (connexin-26) 35delG mutation in the Belgian population using an easy and reliable screening method," Human Mutation, vol. 14, no. 3, pp. 263-266, 1999.

[12] W. Al-Achkar, F. Moassass, B. Al-Halabi, and A. Al-Ablog, "Mutations of the connexin 26 gene in families with nonsyndromic hearing loss," Molecular Medicine Reports, vol. 4, no. 2, pp. 331-335, 2011.

[13] L. Bubbico, A. Rosano, and A. Spagnolo, "Prevalence of prelingual deafness in Italy," Acta Otorhinolaryngologica Italica, vol. 27, no. 1, pp. 17-21, 2007.

[14] M. M. Carrasquillo, J. Zlotogora, S. Barges, and A. Chakravarti, "Two different connexin 26 mutations in an inbred kindred segregating non-syndromic recessive deafness: implications for genetic studies in isolated populations," Human Molecular Genetics, vol. 6, no. 12, pp. 2163-2172, 1997.

[15] J. Zlotogora, "Department of Community Genetics Public Health Services Ministry of Health Israel, Mendelian Disorders in The Non Jewish Population of Israel," 2015, https://www.health.gov.il/Subjects/Genetics/Documents/book non-Jews.pdf.

[16] J. Zheng, Z. Ying, Z. Cai et al., "GJB2 mutation spectrum and genotype-phenotype correlation in 1067 han Chinese subjects with non-syndromic hearing loss," PLOS ONE, vol. 10, no. 6, Article ID e0128691, 2015.

[17] N. A. Barashkov, V. G. Pshennikova, O. L. Posukh et al., "Spectrum and frequency of the GJB2 gene pathogenic variants in a large cohort of patients with hearing impairment living in a subarctic region of Russia (the Sakha Republic)," PLoS ONE, vol. 11, no. 5, Article ID e0156300, 2016. 

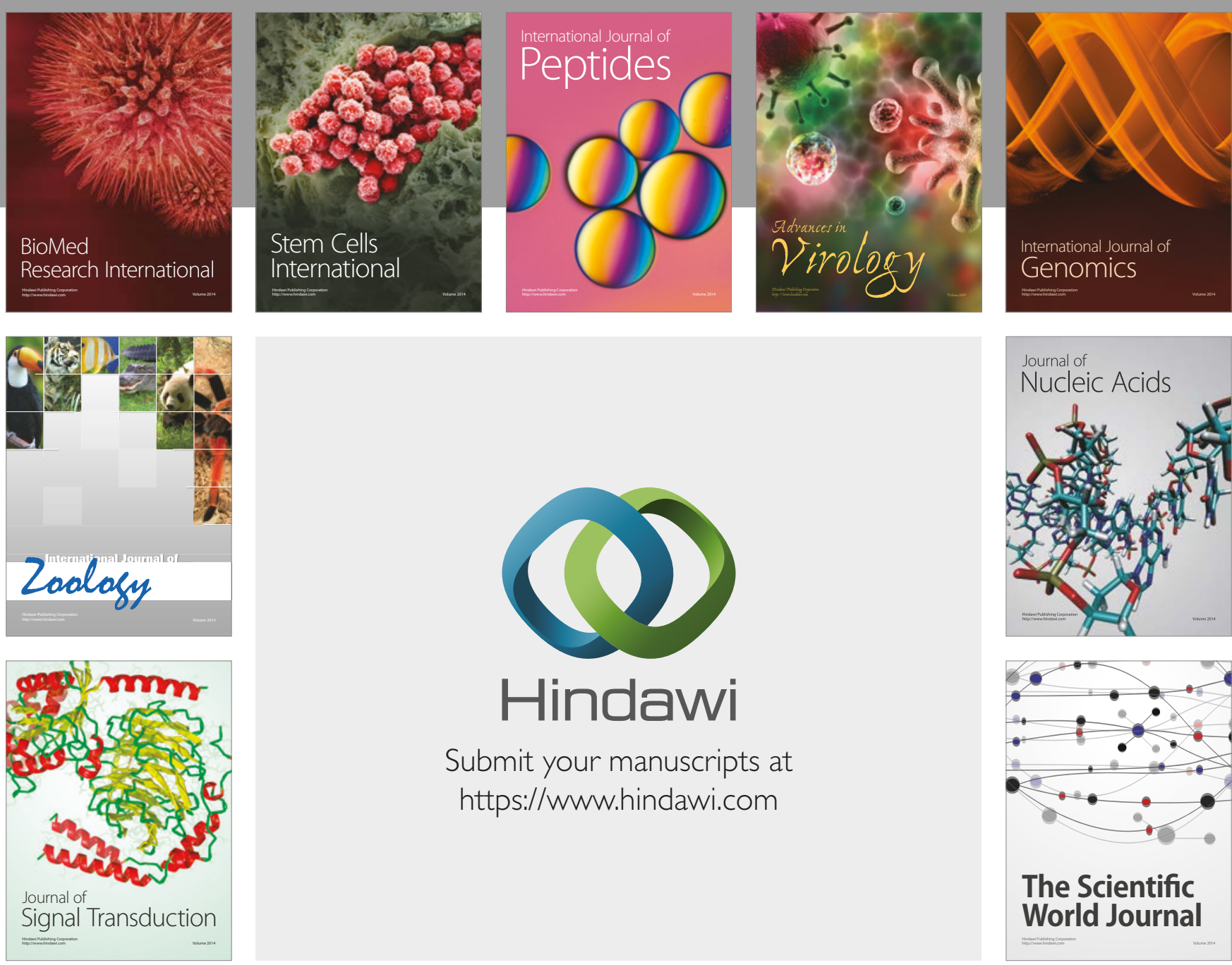

Submit your manuscripts at

https://www.hindawi.com
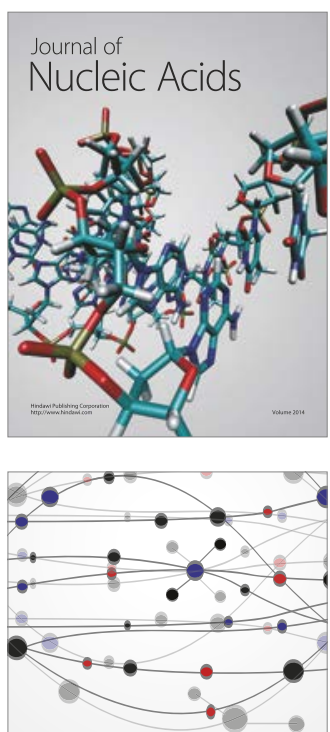

The Scientific World Journal

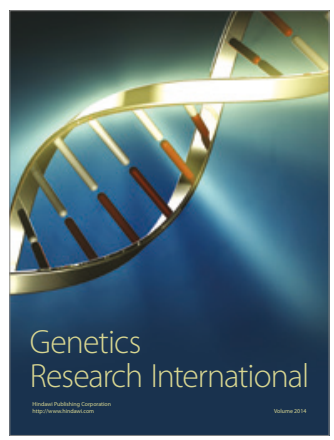

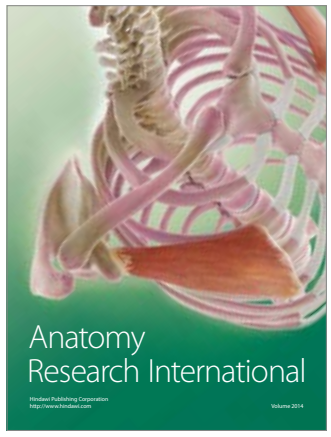

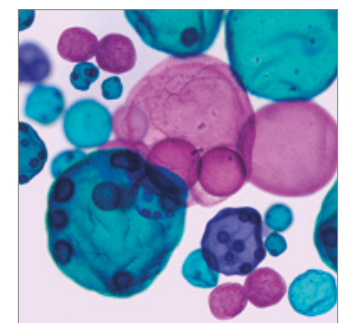

International Journal of Microbiology
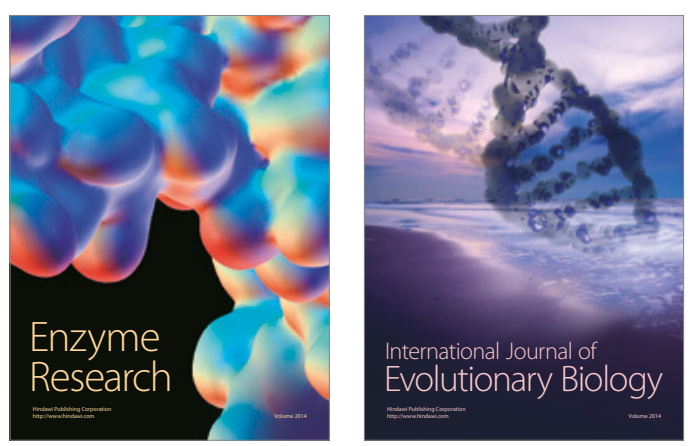
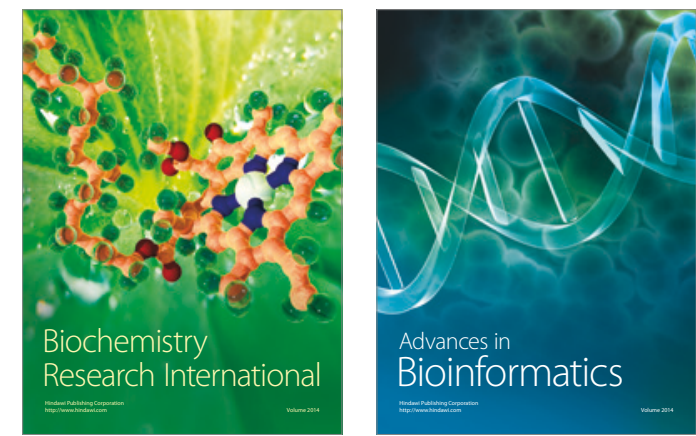

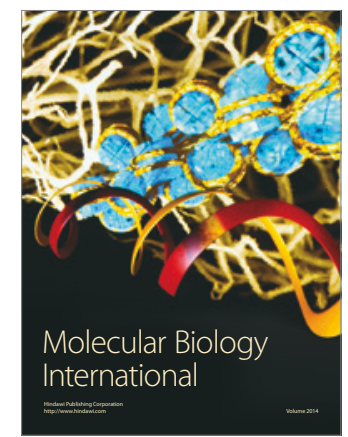

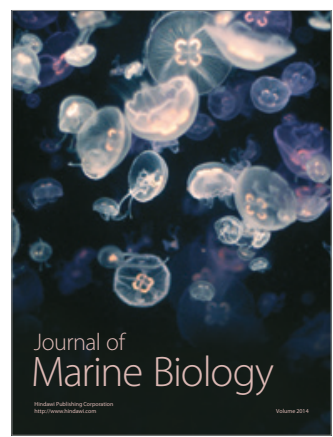

